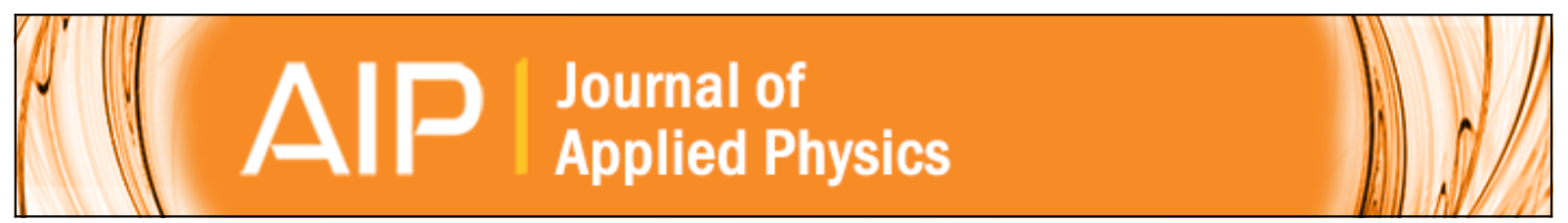

Temperature dependence of ion-beam mixing in crystalline and amorphous germanium isotope multilayer structures

M. Radek, H. Bracht, M. Posselt, B. Liedke, B. Schmidt, and D. Bougeard

Citation: Journal of Applied Physics 115, 023506 (2014); doi: 10.1063/1.4861174

View online: http://dx.doi.org/10.1063/1.4861174

View Table of Contents: http://scitation.aip.org/content/aip/journal/jap/115/2?ver=pdfcov

Published by the AIP Publishing

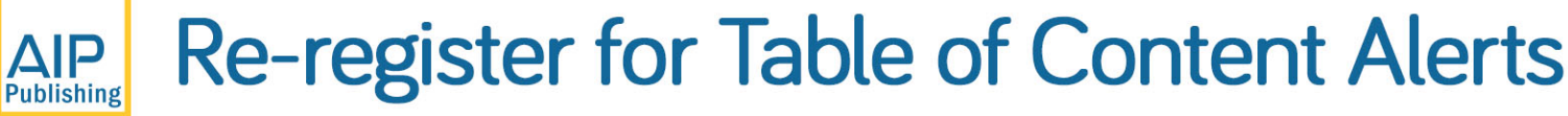

Create a profile.

Sign up today! 


\title{
Temperature dependence of ion-beam mixing in crystalline and amorphous germanium isotope multilayer structures
}

\author{
M. Radek, ${ }^{1}$ H. Bracht, ${ }^{1, a)}$ M. Posselt, ${ }^{2}$ B. Liedke, ${ }^{2}$ B. Schmidt, ${ }^{2}$ and D. Bougeard ${ }^{3}$ \\ ${ }^{1}$ Institute of Materials Physics, Westfälische Wilhelms-Universität Münster, 48149 Münster, Germany \\ ${ }^{2}$ Institute of Ion Beam Physics and Materials Research, Helmholtz-Zentrum Dresden-Rossendorf, \\ Bautzner Landstraße 400, D-01328 Dresden, Germany \\ ${ }^{3}$ Institut für Experimentelle und Angewandte Physik, 93040 Regensburg, Germany
}

(Received 17 December 2013; accepted 18 December 2013; published online 9 January 2014)

\begin{abstract}
Self-atom mixing induced by $310 \mathrm{keV}$ gallium (Ga) ion implantation in crystalline and preamorphized germanium $(\mathrm{Ge})$ at temperatures between $164 \mathrm{~K}$ and $623 \mathrm{~K}$ and a dose of $1 \times 10^{15} \mathrm{~cm}^{-2}$ is investigated using isotopic multilayer structures of alternating ${ }^{70} \mathrm{Ge}$ and ${ }^{\text {nat }} \mathrm{Ge}$ layers grown by molecular beam epitaxy. The distribution of the implanted Ga atoms and the ion-beam induced depth-dependent self-atom mixing was determined by means of secondary ion mass spectrometry. Three different temperature regimes of self-atom mixing, i.e., low-, intermediate-, and high-temperature regimes are observed. At temperatures up to $423 \mathrm{~K}$, the mixing is independent of the initial structure, whereas at $523 \mathrm{~K}$, the intermixing of the preamorphized $\mathrm{Ge}$ structure is about twice as high as that of crystalline Ge. At $623 \mathrm{~K}$, the intermixing of the initially amorphous Ge structure is strongly reduced and approaches the mixing of the crystalline material. The temperature dependence of ion-beam mixing is described by competitive amorphization and recrystallization processes. () 2014 AIP Publishing LLC. [http://dx.doi.org/10.1063/1.4861174]
\end{abstract}

\section{INTRODUCTION}

The availability of highly enriched stable isotopes of, e.g., silicon ( $\mathrm{Si}$ ) and germanium $(\mathrm{Ge})$ enables the preparation of isotopically controlled semiconductors that are advantageous for studying many fundamental material properties. Such studies concern, e.g., the mechanisms of self- and dopant diffusion, ${ }^{1-3}$ the electronic properties and nature of deep defect centers, ${ }^{4}$ the impact of isotopic composition on heat transport, ${ }^{5-7}$ and the ion-beam induced self-atom mixing. ${ }^{8-10}$ Although atomic mixing in solids caused by ion irradiation is a known and widely discussed phenomenon, ${ }^{11-17}$ experimental results on self-atom mixing in semiconductors such as $\mathrm{Si}$ and $\mathrm{Ge}$ are rather limited. Present studies mainly concern ion-beam induced self-atom mixing in $\mathrm{Si}$ and $\mathrm{Ge}$ at room temperature. ${ }^{8-10}$

In our previous work, we described ion-beam induced self-atom mixing in crystalline and amorphous Ge isotope multilayer structures. In this case, both structures were grown by means of molecular beam epitaxy (MBE). ${ }^{10} \mathrm{~A}$ stronger mixing in the crystalline MBE multilayer structure compared to its amorphous counterpart was observed for $300 \mathrm{~K}$. This behavior is at variance to molecular dynamics (MD) simulations of, e.g., Nordlund et al. ${ }^{18}$ In order to test our former results, we prepared an amorphous isotope multilayer from the MBE grown crystalline isotope structure by $\mathrm{Ge}$ implantation. We used this preamorphized Ge structure for comparison of ion-beam mixing in crystalline and amorphous Ge induced by Ga implantation at different temperatures. We demonstrate, in this work, that, depending on the temperature, the ion-beam mixing in preamorphized Ge is

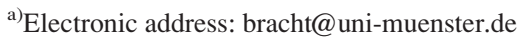

equal to or higher than the mixing in the initially crystalline Ge. This mixing behavior supports the predictions of MD calculations and contradicts our former results obtained by using MBE grown amorphous isotope layers. ${ }^{10}$ The opposite result of our former work published in Ref. 10 is likely affected by contaminations of oxygen and carbon later detected with secondary ion mass spectrometry (SIMS). Our measurements reveal that oxygen and carbon are easily incorporated in MBE grown amorphous Ge by handling in air. It is therefore not representative for pure amorphous Ge.

\section{EXPERIMENTAL}

Crystalline $\left({ }^{\text {nat }} \mathrm{Ge} /{ }^{70} \mathrm{Ge}\right)_{10}$ isotope multilayers were grown by means of MBE. The thickness of each natural and isotopically enriched layer is about $15 \mathrm{~nm}$. The crystalline structure was deposited on a (100)-oriented n-type Ge wafer with a specific resistivity of $40 \Omega \mathrm{cm}$. The preamorphized multilayer structure was prepared by Ge ion implantation into the crystalline isotope structure. The implantation was performed at $77 \mathrm{~K}$ with $310 \mathrm{keV}$ Ge ions, a dose of $7 \times 10^{13} \mathrm{~cm}^{-2}$, and an ion current of $200 \mathrm{nA}$. The amorphization dose of $\mathrm{Ge}$ at $77 \mathrm{~K}$ is about $6 \times 10^{13} \mathrm{~cm}^{-2}$, according to Koffel et al. ${ }^{19}$ Cross-sectional transmission electron microscope (XTEM) measurements of the preamorphized samples reveal complete amorphization up to a depth of about $200 \mathrm{~nm}$. Moreover, a $50 \mathrm{~nm}$ wide defective range is observed beneath the amorphous Ge layer. Figure 1 illustrates ${ }^{74} \mathrm{Ge}$ concentration profiles of the as-grown crystalline (c-Ge: red) and preamorphized (a-Ge: blue) isotope structures measured with SIMS. The SIMS measurements were performed with a TOF-SIMS 5 system in a dual beam mode. Oxygen ions with $1 \mathrm{keV}$ energy were used for sputtering and $25 \mathrm{keV}$ bismuth ions for analysis. The depth of the craters left from the SIMS 


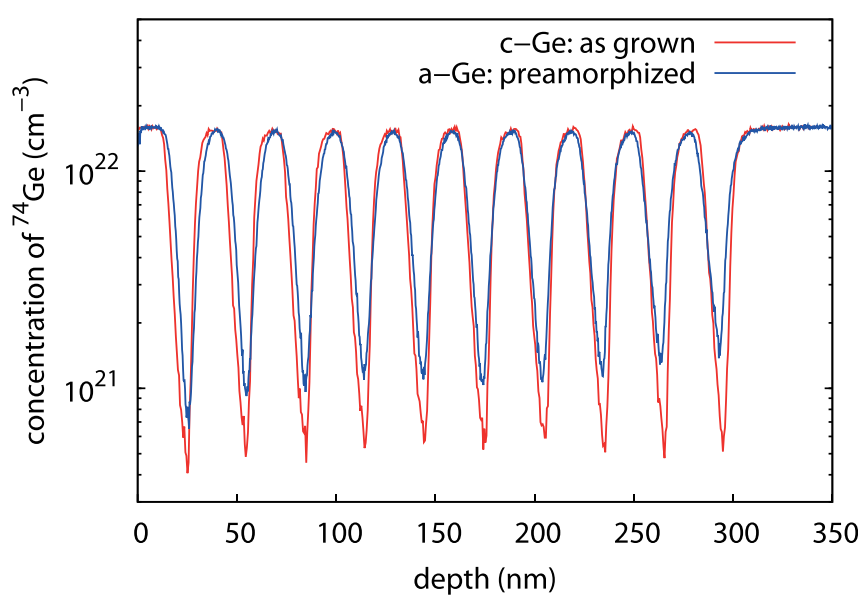

FIG. 1. SIMS concentration profiles of ${ }^{74} \mathrm{Ge}$ of the crystalline (red) and preamorphized (blue) $\left({ }^{\text {nat }} \mathrm{Ge} /{ }^{70} \mathrm{Ge}\right)_{10} \mathrm{MBE}$ multilayer structures.

analysis was determined with an optical profilometer. The sputter time is converted to penetration depths taking into account the crater depth and assuming a constant sputter rate during SIMS profiling. With the well-known abundance of the $\mathrm{Ge}$ isotopes in natural $\mathrm{Ge}$, the detected $\mathrm{Ge}$ ion counts are transformed to concentrations. The obtained concentration profiles of ${ }^{74} \mathrm{Ge}$ are analytically described by the following equation:

$$
C_{\mathrm{Ge}}(x)=C_{1}+\frac{C_{2}-C_{1}}{2} \sum_{i=1}^{20}(-1)^{i+1} \operatorname{erfc}\left(\frac{x-x_{i}}{r_{i}}\right),
$$

where $x$ is the depth, $C_{1}$ and $C_{2}$ are the minimum and maximum concentrations of the ${ }^{74} \mathrm{Ge}$ isotope, and $\operatorname{erfc}(x)=1-\operatorname{erf}(x)$ is the complementary error function. The error function $\operatorname{erf}(x)$ is defined as $\operatorname{erf}(-\infty)=-1$ and $\operatorname{erf}(\infty)$ $=+1 . x_{i}$ represents the depth of the $i$ th isotope interface and $r_{i}$ is a measure of the steepness in the Ge concentration at the $i$ th interface between natural and isotopically enriched $\mathrm{Ge}$ layers.

Ion implantation of $310 \mathrm{keV}$ Ga with a dose of $1 \times 10^{15} \mathrm{~cm}^{-2}$ and an ion current of $200 \mathrm{nA}$ was performed at six different temperatures $(164 \mathrm{~K}, 219 \mathrm{~K}, 300 \mathrm{~K}, 423 \mathrm{~K}$, $523 \mathrm{~K}$, and $623 \mathrm{~K}$ ). The samples are held at these temperatures in the implantation chamber for about $30 \mathrm{~min}$. After implantation, the temperature was rapidly reduced by liquid nitrogen cooling to suppress any post-implantation induced self-atom mixing that could be caused by the dissolution of defect clusters formed during implantation. Due to the construction of the target chamber, all implantations were performed at nearly normal incidence to the (100) sample surface. At $164 \mathrm{~K}$ and $219 \mathrm{~K}$, Ga implantation was only performed into the crystalline Ge isotope structure, whereas both crystalline and preamorphized samples were implanted simultaneously for $\mathrm{T} \geq 300 \mathrm{~K}$.

\section{RESULTS AND DISCUSSION}

Figure 2 shows concentration profiles of ${ }^{74} \mathrm{Ge}$ and ${ }^{69} \mathrm{Ga}$ measured with SIMS after Ga ion implantation in the initially crystalline (red: c-Ge) and preamorphized (blue: a-Ge) Ge isotope structures. The implantations illustrated in this

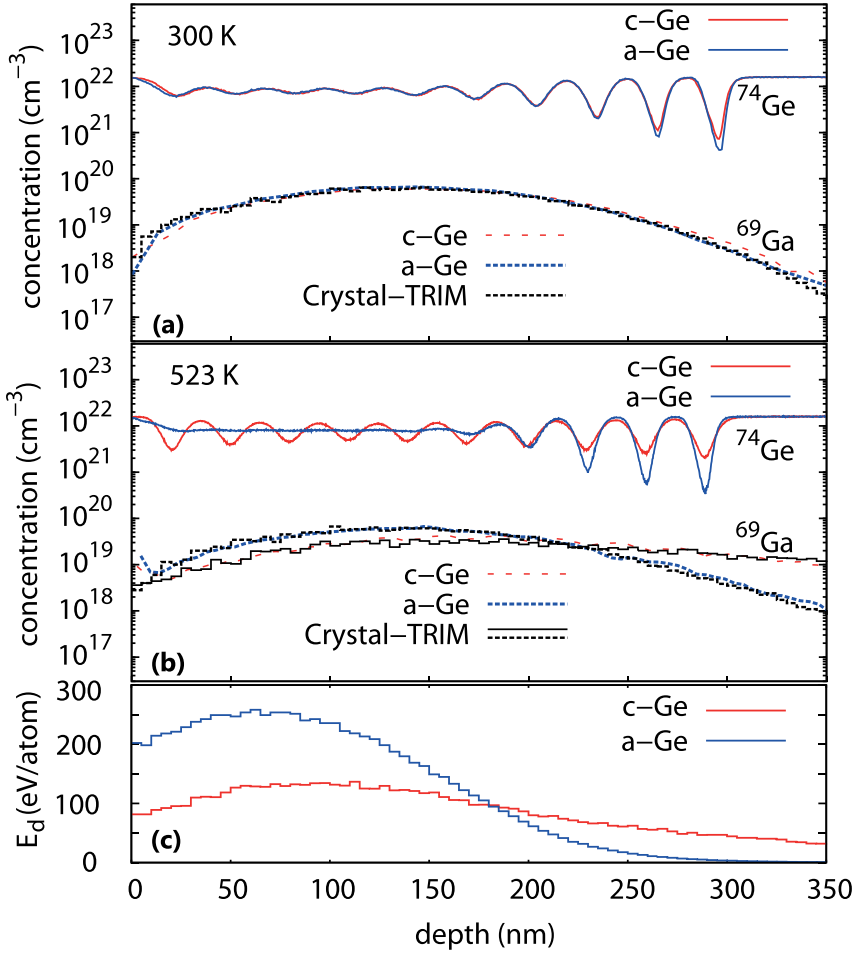

FIG. 2. Concentration profiles of ${ }^{74} \mathrm{Ge}$ (solid lines) and Ga (dashed lines) in initially crystalline (red) and preamorphized (blue) $\left({ }^{\text {nat }} \mathrm{Ge} /{ }^{70} \mathrm{Ge}\right)_{10}$ multilayer structures measured by SIMS after implantation with $310 \mathrm{keV} \mathrm{Ga}$ at a dose of $1 \times 10^{15} \mathrm{~cm}^{-2}$ and temperatures of (a) $300 \mathrm{~K}$ and (b) $523 \mathrm{~K}$. The black dashed line and solid black line (histograms) show the Ga implantation profile predicted by Crystal-TRIM. The depth profile of the nuclear energy deposition per target atom calculated by Crystal-TRIM is illustrated in (c).

figure were performed at $300 \mathrm{~K}$ and $523 \mathrm{~K}$. Figure 2(a) demonstrates that the Ga profile at $300 \mathrm{~K}$ in c-Ge (red dashed-line) is very similar to the $\mathrm{Ga}$ profile in a-Ge (blue dashed-line). Both concentration profiles are reproduced by Crystal-TRIM calculations (e.g., Ref. 20) (black dashed-line) assuming an amorphous target, whose thickness exceeds the amorphous layer of the preamorphized sample. This is in accord with XTEM results showing an amorphous layer of $320 \mathrm{~nm}$ thickness for the $\mathrm{Ga}$ implantation at $300 \mathrm{~K}$. The small difference between the Ga profile in c- and a-Ge is due to channeling during Ga implantation in c-Ge until the structure turns amorphous. At $523 \mathrm{~K}$ (see Fig. 2(b)), the Ga profile of c-Ge strongly deviates from the Ga profile of a-Ge, but is accurately reproduced by Crystal-TRIM calculations assuming a crystalline structure during the whole Ga implantation process. The Ga profile of a-Ge follows the Crystal-TRIM prediction (see black dashed line in Fig. 2(b)) when a $200 \mathrm{~nm}$ thick amorphous layer on top of a crystalline structure is assumed. This thickness equals the width of the damaged layer in the preamorphized Ge. Overall this indicates that $\mathrm{Ga}$ implantation at $523 \mathrm{~K}$ in c- and a-Ge does not induce any significant structural changes, i.e., both the structure of c- and a-Ge samples remains unchanged.

The self-atom mixing at $300 \mathrm{~K}$ in c-Ge, indicated by the ${ }^{74} \mathrm{Ge}$ concentration profiles in Fig. 2(a), is very similar to the mixing in a-Ge. In contrast, the self-atom profiles obtained after $\mathrm{Ga}$ implantation at $523 \mathrm{~K}$ differ strongly across the whole isotope structure as illustrated by Fig. 2(b). A 
comparison between $300 \mathrm{~K}$ and $523 \mathrm{~K}$ reveals that for $x \leq 200 \mathrm{~nm}$, the self-atom mixing in c-Ge at $300 \mathrm{~K}$ is stronger than at $523 \mathrm{~K}$. For $x>200 \mathrm{~nm}$, it is reverse, i.e., the self-atom mixing in c-Ge at $300 \mathrm{~K}$ is weaker than at $523 \mathrm{~K}$. On the other hand, the amorphous Ge structure is clearly stronger mixed at $523 \mathrm{~K}$ than at $300 \mathrm{~K}$ for $x \leq 200 \mathrm{~nm}$, whereas for $x>200 \mathrm{~nm}$, the self-atom mixing of a-Ge at $300 \mathrm{~K}$ and $523 \mathrm{~K}$ is very similar.

The difference in self-atom mixing of c-Ge and a-Ge can be evaluated more quantitatively by modeling the implantation-induced atomic displacements with a convolution integral ${ }^{8}$

$$
C_{\mathrm{Ge}}^{\mathrm{after}}(x)=\int C_{\mathrm{Ge}}^{\mathrm{before}}\left(x^{\prime}\right) \cdot g\left(x-x^{\prime}\right) \cdot d x^{\prime},
$$

where $C_{\mathrm{Ge}}^{\text {before }}(x)$ and $C_{\mathrm{Ge}}^{\mathrm{after}}(x)$ represent the Ge distribution before and after Ga implantation, respectively. $g$ denotes a Gaussian function of the form

$$
g(x)=\frac{1}{\sqrt{2 \pi \sigma}} \exp \left(-\frac{x^{2}}{2 \sigma^{2}}\right) .
$$

The quantity $\sigma$ determines the width of the Gaussian function and is assumed to be depth dependent

$$
\sigma(x)=k \cdot \exp \left(-\frac{(x-l)^{2}}{2 m^{2}}\right)
$$

With Eqs. (2) to (4), the depth dependent ion-beam induced self-atom mixing of the Ge multilayer is described by means of a depth dependent displacement function $\sigma(x)$. The parameters $k, l$, and $m$ are the amplitude, position, and width of the $\sigma(x)$ function. These parameters were optimized to accurately describe the ${ }^{74} \mathrm{Ge}$ concentration profiles. Figure 3 shows best fits to the experimental ${ }^{74} \mathrm{Ge}$ profiles obtained after Ga implantation into c- and a-Ge at $300 \mathrm{~K}$ and $523 \mathrm{~K}$. The corresponding $\sigma(x)$ profiles referred to the right ordinate are also displayed. The similarity of the $\sigma(x)$ profiles at $300 \mathrm{~K}$ (see Fig. 3(a)) expresses the almost identical self-atom mixing in c- and a-Ge at this temperature (see Fig. 2(a)). On the other hand, the disparity of the $\sigma(x)$ profiles at $523 \mathrm{~K}$ (see Fig. 3(b)) indicates the difference in self-atom mixing in cand a-Ge shown in Fig. 2(b). The stronger mixing of a-Ge compared to c-Ge for $x \leq 200 \mathrm{~nm}$ leads to a higher Ge displacement as shown in Fig. 3(b). The higher Ge displacement of c-Ge compared to a-Ge for $x>200 \mathrm{~nm}$ reflects the stronger mixing of c-Ge than of a-Ge. As expected, the Ge displacement $\sigma$ of $\mathrm{c}$ - and a-Ge is in qualitative agreement with the depth profile of the nuclear energy deposition $E_{\mathrm{d}}$ per target atom (see Fig. 2(c)).

The parameters describing the Ge displacement $\sigma(x)$ of all $\mathrm{Ga}$ implanted c- and a-Ge samples investigated in this work are listed in Table I. The amplitude of mixing $k$, i.e., maximum Ge displacement, is shown in Fig. 4 as a function of the sample temperature during ion implantation. The temperature dependence of ion-beam mixing in c- and a-Ge is divided in three temperature regions. In region I, ion-beam mixing in initially crystalline and preamorphized Ge is

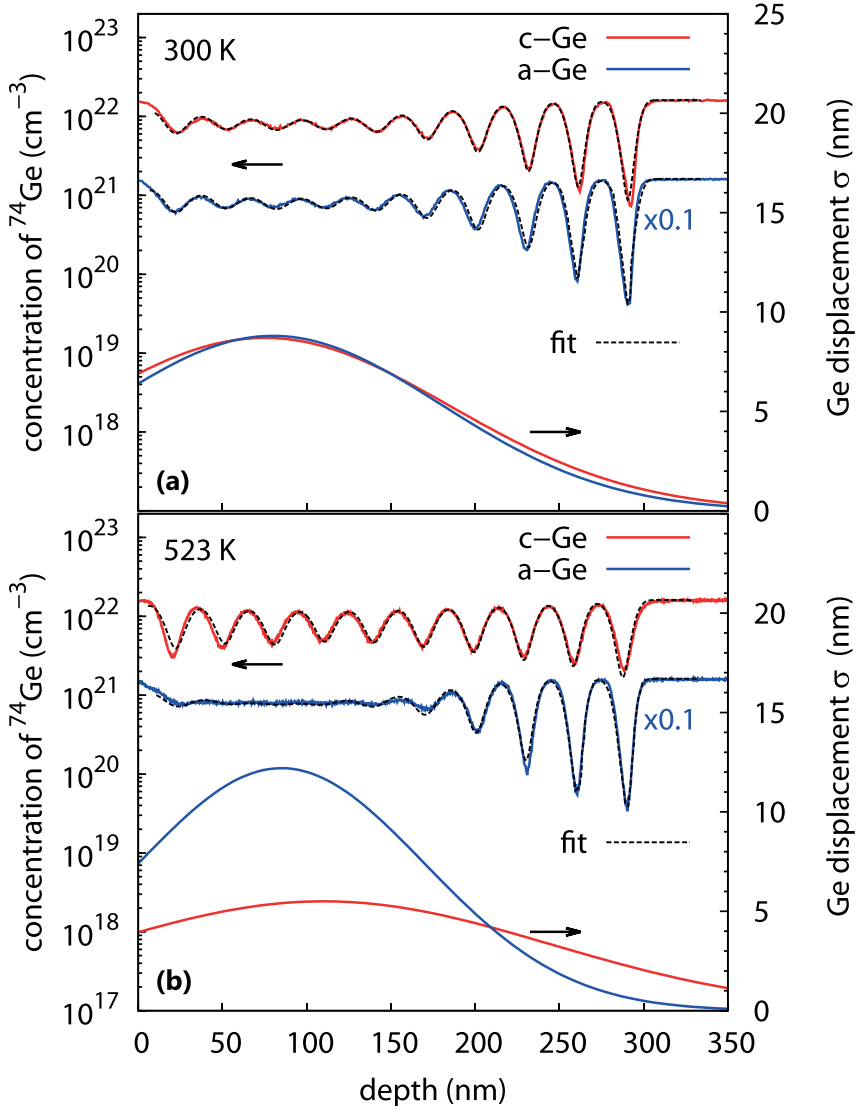

FIG. 3. Best fits (black dashed lines) based on Eqs. (2)-(4) to the Ga-implantation induced self-atom mixing profiles (solid lines) in initially crystalline (red) and preamorphized (blue) Ge at (a) $300 \mathrm{~K}$ and (b) $523 \mathrm{~K}$. The ${ }^{74} \mathrm{Ge}$ concentration profiles of c- and a-Ge are differently scaled for clarity. The lower solid lines in (a) and (b) show the corresponding Ge displacement $\sigma(x)$ determined from the analysis of ion-beam induced self-atom mixing at $300 \mathrm{~K}$ and $523 \mathrm{~K}$, respectively. Note, the Ge displacement $\sigma$ is referred to the right axis. The parameters of the $\sigma(x)$ function of all samples investigated, in this work, are listed in Table I.

nearly equal. Within this region, the Ge displacement increases with temperature. The $k$ values for $\mathrm{c}$ - and a-Ge at $300 \mathrm{~K}$ and $423 \mathrm{~K}$ are equal within the experimental accuracy indicating that the corresponding Ge profiles are very similar (see Fig. 2(a) for $300 \mathrm{~K}$ ). The similar atomic mixing of the initially crystalline and preamorphized sample is a

TABLE I. Fit parameters $k$ (amplitude), $l$ (position), and $m$ (width) of the depth dependent $\sigma(x)$ function deduced from the analysis of self-atom mixing in crystalline and preamorphized Ge isotope multilayers. The mixing of the isotope structure was induced by $310 \mathrm{keV} \mathrm{Ga}$ implantation at a dose of $1 \times 10^{15} \mathrm{~cm}^{-2}$ and temperatures ranging from $164 \mathrm{~K}$ to $623 \mathrm{~K}$.

\begin{tabular}{lllll}
\hline \hline sample & $\mathrm{T}(\mathrm{K})$ & \multicolumn{1}{c}{$k(\mathrm{~nm})$} & $l(\mathrm{~nm})$ & $m(\mathrm{~nm})$ \\
\hline $\mathrm{c}-\mathrm{Ge}$ & 164 & $6.0 \pm 0.3$ & $100 \pm 5$ & $95 \pm 5$ \\
$\mathrm{c}-\mathrm{Ge}$ & 219 & $8.1 \pm 0.3$ & $110 \pm 5$ & $120 \pm 5$ \\
c-Ge & 300 & $8.7 \pm 0.3$ & $75 \pm 5$ & $110 \pm 5$ \\
a-Ge & 300 & $8.7 \pm 0.3$ & $85 \pm 5$ & $85 \pm 5$ \\
c-Ge & 423 & $9.7 \pm 0.3$ & $80 \pm 5$ & $115 \pm 5$ \\
a-Ge & 423 & $10.1 \pm 0.3$ & $85 \pm 5$ & $105 \pm 5$ \\
c-Ge & 523 & $5.5 \pm 0.3$ & $110 \pm 5$ & $135 \pm 5$ \\
a-Ge & 523 & $12.2 \pm 0.3$ & $85 \pm 5$ & $85 \pm 5$ \\
c-Ge & 623 & $6.6 \pm 0.3$ & $120 \pm 5$ & $110 \pm 5$ \\
a-Ge & 623 & $7.5 \pm 0.3$ & $90 \pm 5$ & $118 \pm 5$ \\
\hline \hline
\end{tabular}




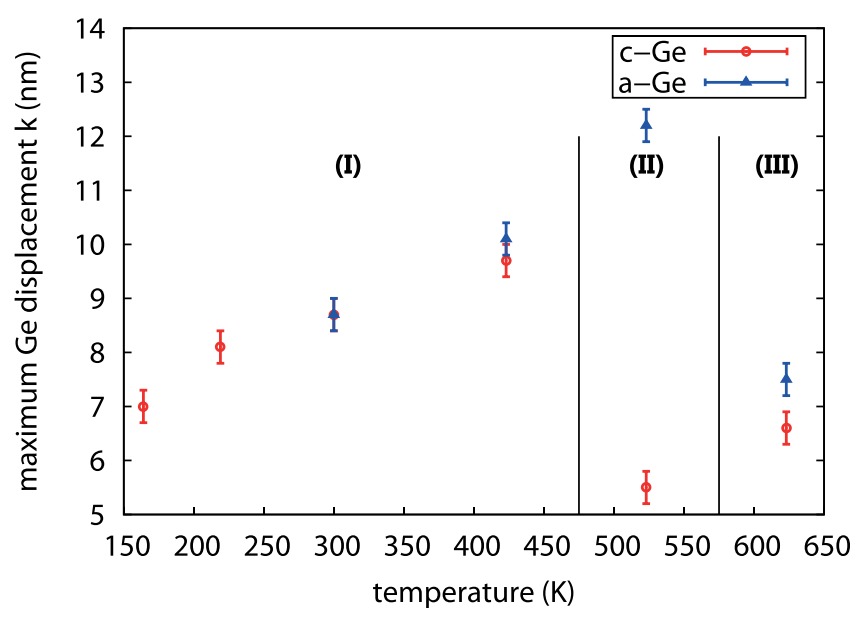

FIG. 4. Temperature dependence of the amplitude $k$ of mixing (maximum Ge displacement), cf. Table I. The mixing of the initially crystalline samples is marked in red, the results for the preamorphized samples are marked in blue. Three temperature regimes (I, II, and III) with different mixing characteristics are identified.

consequence of the amorphization of c-Ge during $\mathrm{Ga}$ implantation. The amorphization threshold of $\mathrm{Ge}$ at $300 \mathrm{~K}$ is reached at a $\mathrm{Ga}$ ion dose of about $6 \times 10^{13} \mathrm{~cm}^{-2} \cdot{ }^{19}$ Considering the total ion dose of $1 \times 10^{15} \mathrm{~cm}^{-2}$, the initially crystalline sample is amorphous during more than $90 \%$ of the ion implantation time. This explains the very similar Ge mixing in the initially crystalline and preamorphized Ge in region $\mathrm{I}$. The slightly stronger Ge mixing in c-Ge compared to a-Ge at $300 \mathrm{~K}$ for $x>200 \mathrm{~nm}$ (see Fig. 2(a)) is due to channeling effects before the crystalline host structure turns amorphous. The non-crystalline state after implantation at $300 \mathrm{~K}$ is confirmed by channeling Rutherford backscattering spectrometry $(\mathrm{RBS} / \mathrm{C}){ }^{21}$ For RBS/C measurements, a collimated $1.7 \mathrm{MeV}$ helium $\left(\mathrm{He}^{2+}\right)$ beam was used. The sample was mounted on a three-axis, high precision $\left( \pm 0.01^{\circ}\right)$ goniometer in a vacuum chamber. The increasing self-atom mixing with increasing temperature observed within region $\mathrm{I}$ is in accord with the thermal spike model (see, e.g., Ref. 15). This model predicts that self-atom mixing mainly takes place during the relaxation stage following the collision cascade. The incident Ga ion transfers its kinetic energy through collisions to the Ge host atoms resulting in locally melted regions. With increasing temperature of the sample, the volume of these areas and the time, the temperature exceeds the melting point increases. Thus, atomic mixing within these regions increases with temperature. It should be mentioned that the thermal spike model must be used for the explanation since a pure ballistic interpretation of the observed self-atom mixing is only possible if unphysically low values for the displacement energy of Ge atoms are assumed. ${ }^{10}$

$\mathrm{RBS} / \mathrm{C}$ measurements of the c-Ge sample implanted at $523 \mathrm{~K}$ reveal that it is crystalline. On the other hand, RBS/C analysis shows that the a-Ge sample remains non-crystalline. Therefore, one can assume that in region II, the initial structure of both samples is not severely modified by the implantation. Within the framework of the thermal spike model, the higher mixing of the amorphous structure compared to its crystalline counterpart can be explained by the lower heat transport capacity and the reduced melting point of a-Ge
(965 K) compared to c-Ge $(1210 \mathrm{~K})$. This interpretation is in agreement with MD calculations of, e.g., Nordlund et al. ${ }^{18}$ The MD simulations reveal that the magnitude of mixing in a-Ge is about a factor of 2 higher than in $\mathrm{c}-\mathrm{Ge}$.

The c-Ge structure shows a more pronounced intermixing for $x>200 \mathrm{~nm}$ at both $300 \mathrm{~K}$ and $523 \mathrm{~K}$ than the a-Ge structure. Since $\mathrm{Ga}$ implantation was performed at nearly $0^{\circ}$ incidence and c-Ge remains crystalline at $523 \mathrm{~K}$, channeling effects lead to higher penetration depths of $\mathrm{Ga}$ and stronger Ge mixing in c- than in a-Ge for $x>200 \mathrm{~nm}$. Figure 2(c) illustrates this by the comparison to the depth profile of the nuclear energy deposition. This quantity is a measure of the intensity of atomic collisions and therefore of the self-atom mixing. It is obvious that at $x>200 \mathrm{~nm}$, the nuclear energy deposition $E_{\mathrm{d}}$ is higher in c-Ge than in a-Ge. The a-Ge samples implanted at $300 \mathrm{~K}$ and $523 \mathrm{~K}$ reveal a similar atomic mixing for $x>200 \mathrm{~nm}$. This indicates similar structures of the samples, most of the time during implantation.

Finally, region III indicated in Fig. 4 is characterized by a self-atom mixing of the preamorphized sample that drops to the level of the crystalline structure. The Ge displacement at $623 \mathrm{~K}$ of a-Ge (c-Ge) is strongly reduced (slightly enhanced) compared to the value at $523 \mathrm{~K}$. As found by $\mathrm{RBS} / \mathrm{C}$, the preamorphized sample turns crystalline during implantation at $623 \mathrm{~K}$. It is very likely that the recrystallization of a-Ge proceeds by solid phase epitaxy (SPE). This can be concluded from the experimental results on the recrystallization velocity in dependence on temperature. ${ }^{22}$ From these data, it follows that at $623 \mathrm{~K}$, the SPE regrowth (SPER) process is sufficiently fast to recrystallize the entire amorphous isotope structure, whereas at $523 \mathrm{~K}$, the recrystallization velocity is still too low. The difference observed in atomic mixing of a- and c-Ge at $623 \mathrm{~K}$ can be explained with the higher mixing efficiency of a-Ge compared to c-Ge until SPE of aGe is completed. However, a SPE induced self-atom mixing could also explain the difference.

\section{CONCLUSION}

Ga implantation induced mixing in initially crystalline and preamorphized Ge isotope multilayer structures were investigated by means of SIMS in combination with RBS/C. A convolution integral method was applied for the quantitative analysis of the self-atom mixing. Three temperature regions were identified in the range of $164 \mathrm{~K}$ to $623 \mathrm{~K}$, which show different mixing characteristics. All observed characteristics of self-atom mixing and of the corresponding $\mathrm{Ga}$ profiles are consistently explained in the framework of the thermal-spike model, channeling effects, amorphization and recrystallization processes, and differences in the heat transport capacity and melting point of the crystalline and preamorphized Ge.

\section{ACKNOWLEDGMENTS}

The authors thank TASCON GmbH in Münster for SIMS measurements, Professor Dr. E. E. Haller for providing the Ge isotopes for the MBE growth, S. Eisenwinder for ion implantation, Dr. R. Heller for RBS analysis, and Dr. R. 
Hübner for XTEM measurements. This work was funded by the Deutsche Forschungsgemeinschaft under Grant Nos. BR 1520/14-1 and PO 436/6-1 as well as an individual Grant No. BR 1520/10-2 within the Heisenberg program for H.B.

${ }^{1}$ H. Bracht, H. H. Silvestri, I. D. Sharp, and E. E. Haller, Phys. Rev. B 75, 035211 (2007).

${ }^{2}$ S. Brotzmann, H. Bracht, J. L. Hansen, A. N. Larsen, E. Simoen, E. E. Haller, J. S. Christensen, and P. Werner, Phys. Rev. B 77, 235207 (2008).

${ }^{3}$ E. Hüger, U. Tietze, D. Lott, H. Bracht, D. Bougeard, E. E. Haller, and H. Schmidt, Appl. Phys. Lett. 93, 162104 (2008).

${ }^{4}$ M. Steger, A. Yang, T. Sekiguchi, K. Saeedi, M. L. W. Thewalt, M. O. Henry, K. Johnston, H. Riemann, N. V. Abrosimov, M. F. Churbanov, A. V. Gusev, A. K. Kaliteevskii, O. N. Godisov, P. Becker, and H.-J. Pohl, J. Appl. Phys. 110, 081301 (2011).

${ }^{5}$ T. Ruf, R. W. Henn, M. Asen-Palmer, E. Gmelin, M. Cardona, H.-J. Pohl, G. G. Devyatych, and P. G. Sennikov, Solid State Commun. 115, 243 (2000); 127, 257 (2003).

${ }^{6} \mathrm{H}$. Bracht, N. Wehmeier, S. Eon, A. Plech, D. Issenmann, J. L. Hansen, A. N. Larsen, J. W. Ager III, and E. E. Haller, Appl. Phys. Lett. 101, 064103 (2012).

${ }^{7}$ H. Bracht, S. Eon, R. Frieling, A. Plech, D. Issenmann, D. Wolf, J. L. Hansen, A. N. Larsen, J. W. Ager III, and E. E. Haller, "Thermal conductivity of isotopically controlled silicon nanostructures," New J. Phys. (to be published).
${ }^{8}$ Y. Shimizu, M. Uematsu, K. M. Itoh, A. Takano, K. Sawano, and Y. Shiraki, Appl. Phys. Express 1, 021401 (2008).

${ }^{9}$ Y. Kawamura, Y. Shimizu, H. Oshikawa, M. Uematsu, E. E. Haller, and K. M. Itoh, Physica B 404, 4546 (2009).

${ }^{10}$ H. Bracht, M. Radek, R. Kube, S. Knebel, M. Posselt, B. Schmidt, and E. E. Haller, J. Appl. Phys. 110, 093502 (2011).

${ }^{11}$ R. Collins, Radiat. Eff. 98(1-4), 1-20 (1986).

${ }^{12}$ Y.-T. Cheng, Mater. Sci. Rep. 5, 45 (1990).

${ }^{13}$ M. Nastasi and J. W. Mayer, Mater. Sci. Eng. R. 12, 1 (1994).

${ }^{14}$ W. Bolse, Mater. Sci. Eng., A 253, 194 (1998).

${ }^{15}$ R. S. Averback and T. D. de la Rubia, Solid State Phys. 51, 281-402 (1997).

${ }^{16}$ C. Jaouen, A. Michel, J. Pacoud, C. Dufour, P. Bauer, and B. Gervais, Nucl. Instrum. Methods Phys. Res. B 148, 176 (1999).

${ }^{17}$ T. Weber and K. P. Lieb, J. Appl. Phys. 73, 3499 (1993).

${ }^{18}$ K. Nordlund, M. Ghaly, and R. S. Averback, J. Appl. Phys. 83, 1238 (1998).

${ }^{19}$ S. Koffel, P. Scheiblin, A. Claverie, and G. Benassayag, J. Appl. Phys. 105, 013528 (2009).

${ }^{20}$ M. Posselt, L. Bischoff, D. Grambole, and F. Herrmann, Appl. Phys. Lett. 89, 151918 (2006).

${ }^{21}$ In Handbook of Modern Ion Beam Material Analysis, edited by J. R. Tesmer, M. Nastasi, J. C. Barbour, C. J. Maggiore, and J. W. Mayer (Materials Research Society, Pittsburgh, 1995).

${ }^{22}$ B. C. Johnson, P. Gortmaker, and J. C. McCallum, Phys. Rev. B 77, 214109 (2008). 